\title{
Influence on Blood Pressure of Renal Isografts between Spontaneously Hypertensive and Normotensive Rats, Utilizing the $F_{1}$ Hybrids
}

\author{
Kazuki Kawabe, M.D.,* Takushi X. Watanabe, M.P., Kumiko \\ Shiono, Ph.D., and Hirofumi Sokabe, M.D.
}

\begin{abstract}
SUMMARY
The $F_{1}$ hybrids $\left(F_{1}\right)$ of spontaneously hypertensive rats (SHR) and Wistar rats $(W)$, whose kidneys were transplanted from SHR at the age of 10 weeks and 20 weeks, showed significant elevation of blood pressure (BP) for 11 weeks after the transplantation. In $F_{1}$ with $W$ or $F_{1}$ kidneys $\mathrm{BP}$ was decreased near to the normal level. $\mathrm{F}_{1}$ whose kidneys were transplanted from SHR or W showed low renin activity both in plasma and the kidney. It is suggested that BP of SHR is probably determined by the renal pro-hypertensive factor(s) other than renin influencing on sympathetic nerves through central nervous systems.
\end{abstract}

\section{Additional Indexing Words :}

Renal transplantation Plasma renin activity Kidney renin activity Denervation of the kidney

$\mathbf{R}^{\mathrm{E}}$ ENAL origin of the hypertensive cardiovascular disease has long been considered by many investigators. According to this concept hypertension may be caused by some dysfunction of the kidney. In hypertension associated with renal diseases, or caused by manipulation of the kidney, no one can doubt its renal origin. Similarly, spontaneous hypertension in rats, as well as essential hypertension in humans, might be induced by some renal dysfunction, although no responsible dysfunction has yet been clarified.

Utilizing the renal transplantation studies, Bianchi et al ${ }^{11}$ and Dahl, Heine, and Thompson ${ }^{2 y}$ disclosed that the kidney of their own strain appeared to determine the level of blood pressure or the susceptibility to hypertension. However, in the spontaneously hypertensive rat (SHR) developed by Okamoto and Aoki, ${ }^{3 /}$ the evidences presently available have not yet been conclusive. In SHR, nervous systems have been vigorously investigated and the increased sympathetic nerve activity has been stated to be the primary cause

From the Urology Section, Sanraku Hospital and the Department of Pharmacology, Jichi Medical School.

* Present address and reprint request to: Kazuki Kawabe, M.D., Department of Urology, Faculty of Medicine, University of Tokyo, Hongo 7-3-1, Bunkyo-ku, Tokyo 113.

Received for publication March 29, 1978. 
of the hypertension of SHR. ${ }^{4)-6)}$

Renal factor in SHR still remains unclear. Glomerular filtration rate (GFR) was varied among the colonies of SHR, ") changes of urine volume and sodium balance have not been confirmed. ${ }^{81,9)}$ On the other hand, the recent reports on sodium and water metabolism showed that exaggerated natriuresis was recognized at least in some phase of hypertension of SHR. ${ }^{10), 11)}$ Decreased excretion of sodium was shown in anesthetized SHR. ${ }^{12)}$ According to the theory of Guyton et al, ${ }^{13)}$ this latter data are explained by the fall of blood pressure (BP) during anesthesia. The BP decrease results in the smaller urinary output in the hypertensive individuals than the normotensives, because there is renal excretory dysfunction in the hypertensives.

The purpose of this study is to elucidate the role of the kidney in the pathogenesis of SHR by exchanging the kidney between the SHR and normotensive Wistar rats $(\mathrm{W})$, utilizing the $\mathrm{F}_{1}$ hybrids.

\section{Materials and Methods}

Male SHR, the offspring $\left(\mathrm{F}_{38-42}\right)$ of original Kyoto SHR, inbred W $\left(\mathrm{F}_{9-13}\right)$, the colony from Wistar Kyoto, and their hybrids $\left(F_{1}\right)$, raised in Biological Research Laboratories, Central Research Division, Takeda Cheimcal Indsutries, were used. The rats were transferred to our laboratory at 6 weeks of age and fed with regular laboratory chow and tap water ad lib.

Blood pressure: Blood pressure (BP) of the rats was determined by the plethysmographic tail method. Measurements were made in triplicate to the nearest $10 \mathrm{mmHg}$. BP was determined weekly until 10 weeks after the transplantation, then the BP was determined directly through the polyethylene tube inserted into the abdominal aorta. ${ }^{14}$ )

Renal transplantation: All the renal transplantations were performed when the rats were at 10 or 20 weeks of age. To prevent allograft reaction, transplantation of the kideny was performed from SHR to $F_{1}$, and from $W$ to $F_{1}$ instead of the direct transplantation from SHR to $\mathrm{W}$ or vice versa. Surgery was performed with the rats under ether anesthesia, utilizing the modified microsurgical technique of Lee. ${ }^{15}$ ) All anastomoses were sutured with $7 / 0$ atraumatic needles. The total ischemia time varied between 30 and $50 \mathrm{~min}$. Heparinized saline, 1 to $2 \mathrm{ml}$, was flushed through the donors' right kidneys immediately before their removal. The recipients were subjected to bilateral nephrectomy at the time of transplantation.

Renin activity: Plasma renin activity (PRA) was determined by the method of Shiono and Sokabe. ${ }^{16)}$ About $1 \mathrm{ml}$ of blood was collected through polyethylene tube inserted into the aorta at the termination of the experiments. Then the kidneys were removed to determine the kidney renin activity (KRA) by the modified method Nishimura and Sokabe. ${ }^{17}$ Renin activity was expressed as the first reaction constant, $\mathrm{K}$, calculated from the following equation:

$$
\mathrm{K}=\left\{2-\log _{10}[100(\mathrm{M}-\mathrm{X} / \mathrm{M})]\right\} 2.3 / \mathrm{t}
$$

where $M$ is the angiotensinogen content of the plasma and $X$ is the angiotensin 
formed during an incubation time, $\mathrm{t}$.

Blood urea nitrogen: Blood urea nitrogen (BUN) was determined with Azostix, a reagent strip for BUN. ${ }^{18)}$ Results were provided directly in $\mathrm{mg}$ urea nitrogen per $100 \mathrm{ml}$ on comparison with color blocks of $10,20,40$, and $60 \mathrm{mg}$ urea nitrogen per $100 \mathrm{ml}$. If color produced fell between the 2 color blocks, the results were interpolated.

The Student t-test was used for statistical analysis. Values given represent the mean and standard error of the mean.

\section{Results}

Course of blood pressure in animals used in this experiment was demon-

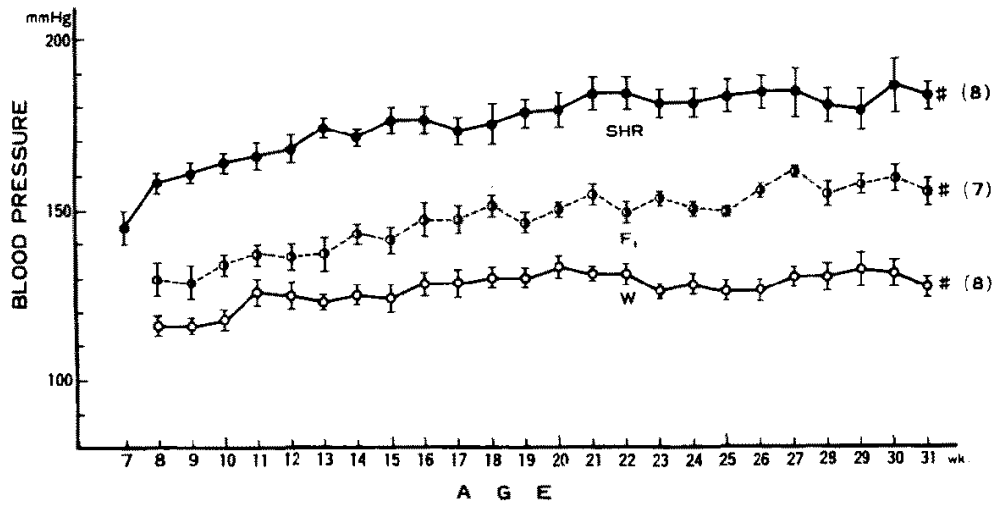

Fig. 1. BP of SHR (0), W (O), and $F_{1}(0)$, determined by the plethysmographic tail method. BP (\#) was determined at the age of 31 weeks through the polyethylene tube inserted into the abdominal aorta. Mean \pm S.E.

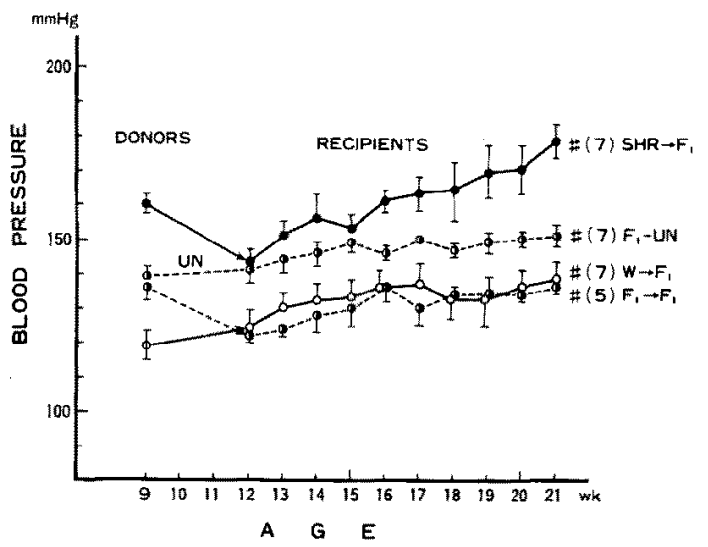

Fig. 2. BP of the bilaterally nephrectomized recipients after the transplantation of the kidneys from the SHR $\left(S H R \rightarrow F_{1}\right), W\left(W \rightarrow F_{1}\right)$, and $F_{1}\left(F_{x} \rightarrow\right.$ $\left.F_{1}\right)$. Transplantation was performed when the donors and recipients were at the age of 10 weeks, $B P$ of $F_{1}$ before the transplantation and after the unilateral nephrectomy ( $\left.\mathrm{F}_{1}-\mathrm{UN}\right)$ were also shown. Symbols are the same as Fig. 1. 
strated in Fig. 1. When the kidneys from SHR aged 10 weeks were transplanted into the $F_{1}$, the recipients developed significantly higher $B P$ than the $F_{1}$ transplanted with $F_{1}$ kidneys $(p<0.001)$, or the unilaterally nephrectomized $F_{1}\left(F_{1}-U N\right)(p<0.001)$. When the kidneys from normotensive $W$ were transplanted into the $\mathrm{F}_{1}, \mathrm{BP}$ fell to lower level than $\mathrm{F}_{1}-\mathrm{UN} \quad(\mathrm{p}<0.03)$ (Fig. 2). In $F_{1}$ who received the $F_{1}$ kidneys (syngrafts) the $B P$ also reduced to normal (Fig. 2). No statistical difference was noted between the BP of $F_{1}$ transplanted with $F_{1}$ and $W$ kidneys (Fig. 2).

These changes in BP after the renal transplantation were essentially the same when the surgery was performed at the age of 20 weeks (Fig. 3). The $B P$ of the $F_{1}$ with SHR kidneys was higher than that of $F_{1}$ with $F_{1}$ kidneys $(p<0.002)$ and that of $F_{1}-U N(p<0.015)$. In $F_{1}$ with $W$ kidneys the BP to reduced also to the lower level than $\mathrm{F}_{1}$-UN ( $\mathrm{p}<0.001$ ) (Fig. 3).

PRA was low in SHR and in $F_{1}$. PRA of the $F_{1}$ whose kidneys had been transplanted from SHR, $F_{1}$, or W was lower than that of $F_{1}-U N$ at the age of 20 weeks, but there were no significant differences between the $F_{1}$ with SHR, $F_{1}$, or W kidneys (Tables I, II). KRA was also low in SHR but was

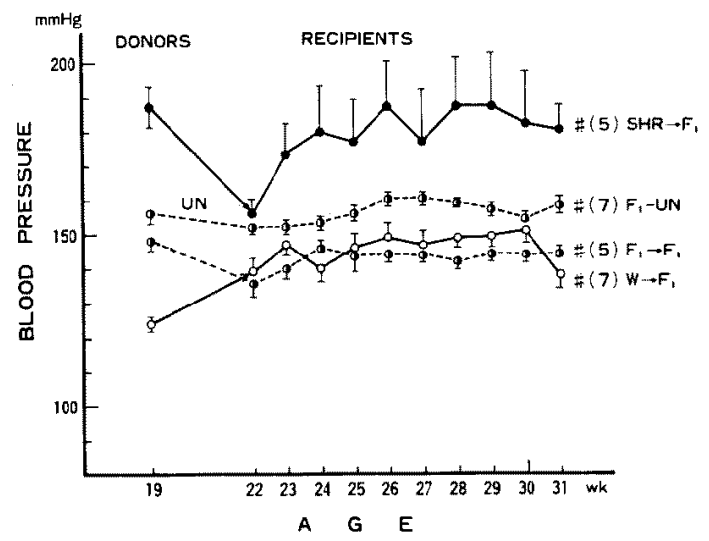

Fig. 3. $B P$ of $F_{1}$ operated when the rats were at the age of 20 weeks. Details are the same as Fig. 2.

Table I. PRA and KRA in W, SHR, and $\mathrm{F}_{1}$

\begin{tabular}{l|c|c|c}
\hline Rats & Age (wk) & PRA* $\left.^{*} \times 10^{-5}\right)$ & KRA* $\left.^{*} \times 10^{-2}\right)$ \\
\hline $\mathrm{W}$ & 20 & $3.69 \pm 0.70(8)$ & $2.80 \pm 0.51(8)$ \\
& 30 & $2.09 \pm 0.67(8)$ & $3.05 \pm 0.28(8)$ \\
$\mathrm{F}_{1}$ & 20 & $2.87 \pm 0.72(7)$ & $2.73 \pm 0.35(7)$ \\
& 30 & $0.80 \pm 0.07(7)$ & $2.39 \pm 0.26(7)$ \\
SHR & 20 & $2.11 \pm 0.20(8)$ & $1.75 \pm 0.17(8)$ \\
& 30 & $1.89 \pm 0.29(7)$ & $2.40 \pm 0.26(8)$
\end{tabular}

* Number of determinations is in parentheses. 
Table II. PRA and KRA in Transplanted $F_{1}$ with $F_{1}, W$, and SHR Kidneys

\begin{tabular}{c|c|c|c}
\hline Rats & Age* $(\mathrm{wk})$ & PRA** $\left.^{* *} \times 10^{-5}\right)$ & KRA** $\left(\mathrm{K} \times 10^{-2}\right)$ \\
\hline $\begin{array}{c}\text { Transplantation } \\
\mathrm{F}_{1} \rightarrow \mathrm{F}_{1}\end{array}$ & 20 & $1.51 \pm 0.38(5)$ & $1.18 \pm 0.42(5)$ \\
& 30 & $1.22 \pm 0.36(5)$ & $1.02 \pm 0.35(5)$ \\
$\mathrm{W} \rightarrow \mathrm{F}_{1}$ & 20 & $1.69 \pm 0.55(7)$ & $0.84 \pm 0.17(7)$ \\
& 30 & $0.49 \pm 0.07(7)$ & $1.00 \pm 0.07(7)$ \\
SHR $\rightarrow \mathrm{F}_{1}$ & 20 & $1.45 \pm 0.59(7)$ & $1.05 \pm 0.11(7)$ \\
& 30 & $0.64 \pm 0.17(7)$ & $0.96 \pm 0.17(7)$ \\
Control & 20 & $2.88 \pm 0.37(7)$ & $1.22 \pm 0.07(7)$ \\
F $_{1}-\mathrm{UN}$ & 30 & $1.20 \pm 0.14(7)$ & $2.84 \pm 0.37(7)$
\end{tabular}

* All rats are at the 10 th week after renal transplantation.

** Number of determinations is in parentheses.

Table III. BUN after Renal Transplantation

\begin{tabular}{c|c|c|c}
\hline Rats & Age* $(w k)$ & No. & BUN (mg \%) \\
\hline Transplantation & & & \\
F $_{1} \rightarrow \mathrm{F}_{1}$ & 20 & 5 & $16.0 \pm 1.0$ \\
& 30 & 5 & $19.0 \pm 1.0$ \\
$\mathrm{~W} \rightarrow \mathrm{F}_{1}$ & 20 & 7 & $27.1 \pm 6.7$ \\
& 30 & 6 & $30.8 \pm 8.2$ \\
SHR $\rightarrow \mathrm{F}_{1}$ & 20 & 7 & $19.3 \pm 3.2$ \\
& 30 & 7 & $40.0 \pm 4.0$ \\
Control & & & $10 \pm 0$ \\
F $_{1}$-UN & 20 & 7 & $17.5 \pm 0.25$
\end{tabular}

* All rats are at the 10 th week after renal transplantation.

insignificant in $\mathrm{F}_{1}$, and was decreased in transplanted kidneys (Tables I, II) BUN was elevated in $F_{1}$ with SHR or $W$ kidneys. But $F_{1}$ with renal syngrafts did not show any high BUN (Table III).

In unilaterally nephrectomized SHR the heart weight/100 Gm body weight was significantly higher than in $W$ at 20 weeks of age $(p<0.001)$, and at 30 weeks of age $(p<0.05)$. In the $F_{1}$ with SHR kidneys, hearts were more hypertrophic at 20 weeks of age $(\mathrm{p}<0.02)$, and at 30 weeks of age $(\mathrm{p}<$ 0.001 ) than in $F_{1}$ transplanted with $F_{1}$ kidneys. These increase in heart weight was parallel with the elevation of BP (Table IV). No marked change in body weight and kidney weight was noted after renal transplantation. 
Table IV. Heart Weight in $\mathbf{W}, \mathbf{F}_{1}, \mathrm{SHR}$, and $\mathbf{F}_{1}-\mathbf{U N}$ and Heart Weight in Transplanted $F_{1}$ with $F_{1}, W$ and SHR Kidneys

\begin{tabular}{|c|c|c|c|}
\hline Rats & Age (wk) & No. & $\begin{array}{c}\text { Heart Weight } \\
(\mathrm{Gm} / 100 \mathrm{Gm} \text { body weight })\end{array}$ \\
\hline \multicolumn{4}{|l|}{ Control } \\
\hline \multirow[t]{2}{*}{ W } & 20 & 8 & $0.236 \pm 0.010$ \\
\hline & 30 & 8 & $0.252 \pm 0.031$ \\
\hline \multirow[t]{2}{*}{$\mathrm{F}_{1}$} & 20 & 7 & $0.248 \pm 0.003$ \\
\hline & 30 & 7 & $0.328 \pm 0.014$ \\
\hline \multirow[t]{2}{*}{ SHR } & 20 & 8 & $0.305 \pm 0.006^{*}$ \\
\hline & 30 & 8 & $0.337 \pm 0.012^{* * *}$ \\
\hline \multirow[t]{2}{*}{$\mathrm{F}_{1}-\mathrm{UN}$} & 20 & 7 & $0.230 \pm 0.03$ \\
\hline & 30 & 7 & $0.342 \pm 0.025$ \\
\hline \multicolumn{4}{|l|}{ Transplantation } \\
\hline \multirow[t]{2}{*}{$\mathrm{F}_{1} \rightarrow \mathrm{F}_{1}$} & 20 & 5 & $0.250 \pm 0.002$ \\
\hline & 30 & 5 & $0.234 \pm 0.009$ \\
\hline \multirow[t]{2}{*}{$\mathrm{W} \rightarrow \mathrm{F}_{1}$} & 20 & 6 & $0.256 \pm 0.010$ \\
\hline & 30 & 7 & $0.270 \pm 0.007$ \\
\hline \multirow[t]{2}{*}{$\mathrm{SHR} \rightarrow \mathrm{F}_{1}$} & 20 & 7 & $0.286 \pm 0.011^{* *}$ \\
\hline & 30 & 7 & $0.340 \pm 0.016^{*}$ \\
\hline
\end{tabular}

\section{Discussion}

The present experiment clearly showed that the kidneys from SHR aged 10 and 20 weeks had the ability to elevate the $\mathrm{BP}$ of recipients $\left(\mathrm{F}_{1}\right)$. In contrast, in $F_{1}$ which were slightly hypertensive the $B P$ reduced to normal when the kidneys from $F_{1}$ (syngrafts) or from $W$ were translanted.

The anti-hypertensive action of normal kidney was not apparent in this experiment. The observed BP decrease may be due to denervation of the kidney and resulted renal vasodilatation. Renal denervation delayed BP increase in SHR. ${ }^{19)}$ We deternimed daily urine volume after the transplantation, but any definite tendency was not found because of large variation. In the previous study on renal infarction hypertension, ${ }_{2}^{20}$ anti-hypertensive action of normal kidney was not apparent before the infarcted kidney was removed. The pro-hypertensive action of the kidney in SHR was equally effective at the age of 10 and 20 weeks. In the infarcted kidney, the action lasted for about 2 weeks after the manipulation. ${ }^{201}$

By the methods of renal transplantation used in this series of experiment, denervation was considered as complete. ${ }^{21)}$ Since the effective plasma flow is well preserved in the isografts, ${ }^{22}$ the elevation of $B P$ of $F_{1}$ transplanted with SHR kidneys was not caused by decreased renal blood flow. But slight hy- 
dronephrotic change and minor histoincompatibility between $F_{1}$ and SHR or $\mathrm{W}$ might cause the increased BUN, although the BP level did not correlate with the disturbance of renal function.

Bianchi et al" found that the hypertension had developed when the kidneys from spontaneously hypertensive rats of their own strain were transplanted into the normotensive ones, while the kidneys from the normotensive rats normalized the $\mathrm{BP}$ of the hypertensive rats. Similarly, Dahl, Heine, and Thompson ${ }^{2}$ observed that inclination or resistance to hypertension was transferred following the renal transplantation between salt-sensitive, hypertensive-prone and salt-resistant rats. Thus the kidney decides the level of BP in these strains, possibly through some changes in salt and water metabolism by the kidney. ${ }^{23)}$ On high salt diet, the transplanted normal kidneys lost their anti-hypertensive action in the studies of both Bianchi et al ${ }^{11}$ and Dahl et al. ${ }^{2}$ )

In the present study PRA in SHR and $F_{1}$ was low in accordance with the previous report. ${ }^{16)}$ PRA and KRA were low in $F_{1}$ with renal grafts, because of the renal denervation. ${ }^{24)}$ In any event renin did not appear to determine the level of BP.

Our results together with previous transplantation experiments quoted above indicate that the hypertensive kidney releases some pro-hypertensive factor(s) other than renin. In SHR the factor may influence the central nervous system and increase the sympathetic nervous activity, as has been reported.4)-6) This unknown factor can be sodium chloride, on the other hand. The SHR or other hypertensive kidneys have some excretory defect, and retain sodium chloride in the body. Thus BP increases to compensate this excretory defect by the mechanism proposed by Guyton et al. ${ }^{13)}$ In fact SHR excreted less water and sodium in an anesthetized condition, ${ }^{13}$ ) in which the systemic BP was decreased. ${ }^{16)}$ However, much remianed to be clarified on renal excretory function of SHR.

Renal excretory functional disturbance in SHR may be congenital. Coleman et al, in contrast, suggested that the increased sympathetic nervous activity compromised the renal function in relatively early life. ${ }^{25}$ ) If so, it must be completed before 10 weeks of age, because the renal denervation was complete in our methods. ${ }^{211}$

The present study supports the view to consider human essential hypertension of renal origin. ${ }^{26)}$ No essential differences between SHR and essential hypertension have yet been found until today.

\section{ACKNOWLEDGements}

The authors appreciate Dr. Suzuoki and his associates, Biological Research 
Laboratories, Central Research Division, Takeda Chemical Industries, Osaka, for the generous supply of the animals. We also thank Mrs. Mitsuko Sokabe and Miss Yukie Kurihara for their expert technical assistances.

\section{REFERENGES}

1. Bianchi G, Fox U, Di-Francesco GF, Giovanetti AM, Pagetti D: Blood pressure changes produced by kidney cross-transplantation between spontanesouly hypertensive rats and normotensive rats. Clin Sci Mol Med 474: 35, 1974

2. Dahl LK, Heine $M$, Thompson $K$ : Genetic influence of the kidneys on blood pressure. Evidence from chronic renal homografts in rats with opposite predispositions to hypertension. Circulat Res 34: 94, 1974

3. Okamoto K, Aoki K: Development of a strain of spontaneously hypertensive rats. Jap Circulat J 27: 282, 1963

4. Okamoto K, Nosaka S, Yamori Y, Matsumoto M: Participation of neural factor in the pathogenesis of hypertension in the spontaneously hypertensive rat. Jap Heart $\mathbf{J}$ 8: 168, 1967

5. Judy WV, Watanabe AM, Henry DP, Besch HR, Murphy WR, Hockel GM: Sympathetic nerve activity. Role in regulation of blood pressure in the spontaneously hypertensive rat. Circulat Res 38 (suppl II): II-21, 1976

6. Yamori $\mathrm{Y}$ : Interaction of neural and nonneural factors in the pathogenesis of spontaneous hypertension. in The Nervous System in Arterial Hypertension, ed by Julius S, Esler MD, Charles c Thomas, Springfield, p17-50, 1976

7. Mullins MM, Banks RO: Age related changes in Na excretion in saline-loaded spontaneously hypertensive rats. Am J Physiol 231: 1364, 1976

8. Matsunaga M, Yamamoto J, Komuro T, Hara A, Yamori Y, Saito N, Ogino K: Plasma renin and vascular complications in substrains of the spontaneously hypertensive rat, with a reference to water and electrolyte balance. Jap Circulat J 40: 889, 1976

9. Nagaoka A, Iwatsuka H, Suzuoki Z, Okamoto K: Electrolyte metabolism in substrains of spontaneously hypertensive rats. Jap Heart J 14: 157, 1973

10. Willis LR, McCallum PW, Higgins JT: Exaggerated natriuresis in the conscious spontaneously hypertensive rat. J Lab Clin Med 87: 265, 1976

11. Kawashima K, Shiono K, Sokabe $\mathrm{H}$ : Plasma renin activity and excretion of water and electrolytes in stroke-prone SHR rats. XIIIth Annual Meeting of the Council for SHR, October 30, 1977, Ehimeken

12. Farman N, Bonvalet JP: Abnormal relationship between sodium excretion and hypertension in spontaneously hypertensive rats. Pflügers Arch Europ Physiol 354: 39, 1975

13. Guyton AC, Colcman TG, Cowley AW Jr, Scheel KW, Manning RD, Norman RA: Arterial pressure regulation. Overiding dominance of the kidneys in long-term regulation and in hypertension. Am J Med 52: 584, 1972

14. Mizogami S, Shibayama F, Kikuchi H, Sokabe H: Effect of anesthesia on blood pressure in hypertensive rats. Jap .J Constitut Med 32: 59, 1969

15. Lee S: An improved technique of renal transplantation in the rat. Surgery 61:771, 1967

16. Siono $\mathrm{K}$, Sokabe $\mathrm{H}$ : Renin-angiotensin system in spontaneously hypertensive rats. Am J Physiol 231: 1295, 1976

17. Nishimura $\mathbf{H}$, Sokabe $\mathrm{H}$ : Inhibition of angiotensinase in the rat plasma and kidney. Jap Heart J 9: 494, 1968

18. Bold AM, Menzies IS, Walker G: An assessment of the Azostix strip test. J Clin Path 23: 85,1970

19. Liard J-F: Renal denervation delays blood pressure increase in the spontaneously hypertensive rat. Experientia 33: 339, 1977

20. Kawabe K, Shiono K, Mizogami S, Sokabe H: Role of the kidney in the development and 
maintenance of hypertension caused by renal segmental infarction in the rat. Jap Heart $J$ 17: 768,1976

21. Norvell JE, Weitsen HA, Sheppek CG: The intrinsic innervation of human renal homotransplants. Transplantation 9: 168, 1970

22. Guttmann RD, Lindquist RR, Parker RM, Carpenter CB, Merrill JP: Renal transplantation in the inbred rat. I. Morphologic, immunologic, and functional alterations during acute rejection. Transplantation 5:668, 1967

23. Bianchi G, Baer PG, Fox U, Duzzi L, Pagetti D, Giovannetti AM: Changes in renin, water balance, and sodium balance during development of high blood pressure in genetically hypertensive rats. Circulat Res 36, 37 (suppl I): 1-153, 1975

24. Stella A, Zanchetti A: Effects of renal denervation on renin release in response to tilting and furosemide. Am J Physiol 232: H500, 1977

25. Coleman TG, Manning RD, Norman RA, DeClue J: The role of the kidney in spontaneous hypertension. Am Heart J 89: 94, 1975

26. Coleman TG, Guyton AC, Young DB, DeClue JW, Norman RA Jr, Manning RD Jr; The role of the kidney in essential hypertension. Clin Exp Pharmacol Physiol 2: 571, 1975 